\title{
STUDY OF EPIDEMIOLOGICAL FACTORS IN CRYPTOSPORIDIOSIS IN CHILDREN WITH DIARRHOEA
}

Farhat Tahira, Haris M. Khan, Indu Shukla, Fatima Shujatullah. M. Ashraf Malik, Nazish Fatima

\author{
1. Assistant Professor, Department of Microbiology, Career Institute of Medical Sciences and Hospital, \\ Lucknow, U.P., India. \\ 2. Professor, Department of Microbiology, J. N. Medical College, AMU, Aligarh, U.P., India. \\ 3. Chair Person, Department of Microbiology, J. N. Medical College, AMU, Aligarh, U.P., India. \\ 4. Assistant Professor, Department of Microbiology, J. N. Medical College, AMU, Aligarh, U.P., India. \\ 5. Professor, Department of Paediatrics, J. N. Medical College, AMU, Aligarh, U.P., India. \\ 6. Assistant Professor, Department of Microbiology, J. N. Medical College, AMU, Aligarh, U.P., India.
}

\section{CORRESPONDING AUTHOR}

Dr. Farhat Tahira, Career Institute of Medical Sciences and Hospital, Sitapur-Hardoi Bypass Road, Ghaila,

Lucknow, U. P., India.

E-mail: farhat_thr@yahoo.co.in, Ph: 00919936349890.

ABSTRACT: BACKGROUND: Cryptosporidium has emerged as one of the major parasitic agents as a cause of diarrhoea in children. Various epidemiological factors have been described by different workers. Aims: This study was done to determine different epidemiological factors incriminated in cryptosporidiosis. Methods: Stool samples from 240 children with diarrhoea were examined for presence of Cryptosporidium. Wet mount examination, modified ZiehlNeelsen (Z.N.) and Safranine-methylene blue staining methods were performed. For 177 samples, ELISA was also done. Detailed history of patients regarding their socioeconomic status and various sociodemographic factors was taken. Statistical Analysis: Chi-square and z tests were used to compare differences between the groups. A p value of $\leq 0.05$ was considered significant. Results: Majority of patients were in Class IV socioeconomic group. Top-feeding, use of insanitary wells for drinking purposes, close association with animals, field defaecation and residence in rural areas were different factors that contributed to the spread of infection. Oocysts were present in 21 children on different staining procedures and 23 were positive by ELISA. Conclusion: Different sociodemographic factors like improper sanitation practices, drinking contaminated water, early withdrawal of breast feeding and close intimacy with animals are various factors that can enhance the spread of infection in community. Preventive measures are of great importance in control of spread of infection as there is no specific therapy for cryptosporidiosis.

KEYWORDS: Cryptosporidium, children, diarrhoea, socioeconomic status, sociodemographic factors

INTRODUCTION: Diarrhoea accounts for childhood morbidity and mortality in developing countries like India. In our country, every year about one million cases of diarrhoea are reported in children1. Besides other causes of bacterial and parasitic infectious diarrhoeas, Cryptosporidium has emerged as one of the major causes of diarrhoea in immunocompetent and immunocompromised children ${ }^{2}$. Cryptosporidium is a coccidian protozoan parasite found in the brush border of enterocytes of the small intestine in many vertebrates, including humans ${ }^{3}$. Cryptosporidiosis can induce self-limiting diarrhoea in immunocompetent persons 
but potentially life-threatening diarrhoea in immunocompromised persons, especially those with AIDS, transplant recipients, those receiving chemotherapy, institutionalized patients and patients with other immunosuppressive infectious diseases ${ }^{4}$. Infection by this parasite accounts for up to 6 percent of all diarrhoeal disease in immunocompetent persons. The infection is also present in up to 24 percent of persons with both AIDS and diarrhoea worldwide ${ }^{5}$.

The best-documented routes of transmission are waterborne, food borne, and person-toperson spread. The majority of the documented outbreaks of waterborne infection in the world have been attributed to contaminated drinking water supplies, although contaminated water used for recreational activities has also been implicated ${ }^{4}$. Diagnosis of infection generally requires observation of infective stage (oocysts) by microscopic examination of faeces by using different types of staining methods like modified Z.N. and safranine-methylene blue and immunoflourescence with monoclonal antibodies ${ }^{6,5,7}$.

This study was undertaken to determine the relevance of various epidemiological factors in transmission of cryptosporidial infection in children with diarrhoea. The different epidemiological factors studied in this study were age, sex, socio-economic status and sociodemographic characteristics.

MATERIAL AND METHODS: The present study was carried out in the Department of Microbiology for the detection of Cryptosporidium on stool samples from children attending the out-patient and in-patient sections of Department of Paediatrics at J. N. Medical College, AMU, Aligarh over a period of 15 months. A total of 240 children upto the age of 12 years suffering from acute, persistent and chronic diarrhoea were selected as cases. Fifty age and sex matched children attending the outpatient department of Paediatrics during the period of study with no symptoms of gastrointestinal disorder for a period of at least one month were selected as controls.

A detailed history was taken after taking informed consent from one of the parents or guardians for socioeconomic status, breast-feeding, locality, source of water supply and types of latrines used and physical examination was done before collecting the stool specimen. All the samples were subjected to various diagnostic procedures like wet mount examination ${ }^{8}$, modified Z.N. ${ }^{9}$ and safranine-methylene blue staining methods ${ }^{10}$ and ELISA for the detection of Cryptosporidium.

For statistical analysis, Chi-square and $\mathrm{z}$ tests were used. A p value of $\leq 0.05$ was considered significant.

RESULT: The wet mount examination and staining techniques were conducted on all the 240 stool samples. ELISA test was performed for detection of Cryptosporidium antigen in 177 stool specimens. Out of 240 stool specimens processed for detection of Cryptosporidium species, 16 were positive by the wet mount examination and 21 were positive by both the staining techniques. Out of 177 samples subjected to ELISA, 23 were positive. Since no 'gold standard' for the detection of Cryptosporidium oocysts in human stool specimens has yet been established ${ }^{11}$, we considered cryptosporidiosis to be a definite diagnosis if the organisms were found in any two of the four techniques employed. There were 21 samples out of 177 for which confirmed identification was made by any two of the tests. The overall prevalence of Cryptosporidium was found to be $11.8 \%$ in this area.

The highest prevalence of Cryptosporidium was found in the age group $0-2$ years $(57.14 \%)$ and no significant difference was found in the detection rates between the two sexes

Journal of Evolution of Medical and Dental Sciences/Volume1/Issue5/November-2012Page-788 
( $p>0.05$ ) (Table I). The positivity of Cryptosporidium cases increased from $9.41 \%$ to $28.57 \%$ as the social class decreased from III to V. Thus the lower socioeconomic classes comprised of the maximum number of Cryptosporidium positive cases (Table II). Children who were bottle-fed showed high prevalence of infection (15.4\%). Most of the patients who were positive were residing in rural areas and were using insanitary wells for purpose of drinking water. Majority of these patients were using insanitary latrines $(16.7 \%)$ and $18.2 \%$ had animals at their residence (Table III).

DISCUSSION: Cryptosporidium should be regarded as a major public health problem as there are reports of major outbreaks of cryptosporidiosis in the United States, the United Kingdom, and Australia due to contamination of drinking water supplies ${ }^{4,13}$.

In this study, Cryptosporidium oocysts were detected in $21(11.86 \%)$ children out of 177 with diarrhoea and none of the controls. Cryptosporidium was found at a higher frequency in the lower socioeconomic classes. Saredi et al. $^{2}$ and Nagamani et al. ${ }^{14}$ have also shown that majority of the children in their respective studies belonged to lower socioeconomic group. The prevalence of Cryptosporidium was higher in those children being or having been bottle-fed $(15.4 \%)$ or receiving liquids or foods in addition to breast milk (12.3\%) than those children on exclusive breast feeding (5.1\%). This finding is in concurrence with the findings of other workers ${ }^{15,16,17 .}$

The rate of infection in children who lived in rural areas was $12.5 \%$ whereas in children from urban areas, it was slightly lower $(11.2 \%)$. Similar rural to urban variations in infection rates is reported by Mahgoub et al.18 and Urbina et al. ${ }^{19}$ in their respective studies. This is attributed to the insanitary living conditions in slum areas - paucity of clean drinking water supplies, mixed dwelling habits (i.e. domestic/pet animals are kept near or inside the houses), improper sewage or waste disposal facilities, intake of contaminated food, etc. ${ }^{20}$. It was found that the rate of infection among those who drank from wells was $42.9 \%$, compared to those who had access to hand pump (6.4\%) and tap water (7.3\%). No case was found in children who drank boiled or filtered water. Unsafe drinking water as a source of infection was reported by other workers also ${ }^{2,21,22}$.

Close contact with animals has been found to be a predisposing factor for infection; the infection rate was $18.2 \%$ among children in close vicinity to animals in comparison with $9.8 \%$ among those who lived in compounds with no animals. Spread of Cryptosporidium from an animal source was documented in other studies also 18,21 . Among the children who went to open fields for disposal of excreta, the infection rate was $16 \%$ while it was $16.7 \%$ for insanitary latrine users. However, only $7.1 \%$ children who used sanitary latrines were infected.

CONCLUSIONS: This study highlights the importance of sociodemographic factors affecting the rate of Cryptosporidium infection. The poor sanitary conditions prevailing in our country may contribute to the disease burden. Since there is no effective, specific therapy against infection with this parasite, preventive measures are of great importance. Such measures include extensive hand washing, avoiding direct contact with stool from animals or humans, avoiding the accidental ingestion of water used in recreational activities, and taking measures to ensure the safety of the drinking water.

\section{REFERENCES:}


1. Govt. of India (2006), Health Information of India 2005, Ministry of Health And Family Welfare, New Delhi.

2. Saredi N, Bava J. Cryptosporidiosis in pediatric patients. Rev Inst Med Trop S Paulo 1998; Vol. 40 No. 3.

3. Tzipori S. Cryptosporidiosis in animals and humans. Microbiol Rev 1983;47:84-96.

4. Fayer R, Morgan U, Upton SJ. Epidemiology of Cryptosporidium: transmission, detection and identification. Int J Parasitol 2000; 30 (12-13): 1305-22.

5. Guerrant RL. Cryptosporidiosis: an emerging, highly infectious threat. Emerg Infect Dis 1997;3:51-57.

6. Guardis M del V- Cryptosporidiosis. In: Basualdo JA; Coto CE \& de Torres RA. Microbiologia biomedica. Buenos Aires, Editorial Atlante SRL, 1996; 943-947.

7. Hendrickson DA and Krenz HM - Reagents and stains. In: Ballows A; Husler WJ; Hermann KL; Isemberg HD \& Shadowy HJ. Manual of clinical microbiology. 5. ed. Washington, American Society for Microbiology, 1991;1289-1314.

8. Basic Laboratory Methods in Medical Parasitology. WHO, Geneva 1991;9-33.

9. Henriksen SA, Pohlenz JFL. Staining of cryptosporidia by a modified Ziehl-Neelsen technique. Acta Vet Scand 1981;22:594-596.

10. Baxby D, Blundell N. Sensitive, rapid, simple methods for detecting Cryptosporidium in faeces. Lancet 1983;ii:1149.

11. Weber R, Bryan RT, Bishop HS, Wahlquist SP, Sullivan JJ, Juranek DD. Threshold of detection of Cryptosporidium oocysts in human stool specimens: evidence for low sensitivity of current diagnostic methods. J Clin Microbiol 1991;29:1323-1327.

12. Bhaskara Rao T. (2002). Sociology of Medicine. $1^{\text {st }}$ Edition, pp.76.

13. Meinhardt PL, Casemore DP, Miller KB. Epidemiologic aspects of human cryptosporidiosis and the role of waterborne transmission. Epidemiol Rev 1996;18:118136.

14. Nagamani K, Rajkumari A, Gyaneshwari. Cryptosporidiosis in a tertiary care hospital in Andhra Pradesh. Indian J Med Microbiol 2001;19:215-216.

15. Sethi S, Sehgal R, Malla N, Mahajan RC. Cryptosporidiosis in a tertiary care hospital. Natl Med J India 1999;12:207-9.

16. Abdel-Messih IA, Wierzba TF, Abu-Elyazeed R, Ibrahim A, Ahmed SF, Kamal K, et al. Diarrhoea associated with Cryptosporidium parvum among young children of the Nile River Delta in Egypt. J Trop Pediatr 2005;51:154-159.

17. Adamu H, Endeshaw T, Teka T, Kifle A, Petros P. The prevalence of intestinal parasites in paediatric diarrhoeal and non-diarrhoeal patients in Addis Ababa hospitals, with special emphasis on opportunistic parasitic infections and with insight into the demographic and socio-economic factors. Ethiopian J Health Dev 2006;20:39-46.

18. Mahgoub ES, Almahbashi A, Abdulatif B. Cryptosporidiosis in children in a north Jordanian paediatric hospital. East Mediterr Health J 2004;10:494-501.

19. Urbina A, Mata L, Pizarro D. Cryptosporidium en ninos de Costa Rica: cuadro clinico, variacion estacional y tratamiento. Acta Med Costarric. 1984;27:191-198.

20. Palit A, Sur D, MitraDhar K, Saha MR. Asymptomatic Cryptosporidiosis in a Periurban Slum setting in Kolkata, India - a Pilot Study. Jpn J Infect Dis 2005;58:110-111.

21. Gambhir LS, Jaiswal JP, Nath G. Significance of Cryptosporidium as an aetiology of acute infectious diarrhoea in elderly Indians. Trop Med Int Health 2003;8:415-419. 
22. Solorzano-Santos F, Penagos-Paniagua M, Meneses-Esquivel R, Miranda-Novales MG, Leanos-Miranda B, Angulo-Gonzalez D, et al. Cryptosporidium parvum infection in malnourished and non malnourished children without diarrhoea in a Mexican rural population. Rev Invest Clin 2000;52:625-31.

TABLE I AGE AND SEX DISTRIBUTION OF CHILDREN EXCRETING CRYPTOSPORIDIUM ( $\mathrm{n}=177)$

\begin{tabular}{ccccc}
\hline $\begin{array}{c}\text { Age group (in } \\
\text { yrs) }\end{array}$ & Specimens examined & \multicolumn{3}{c}{ Cryptosporidium detected } \\
& & Male (\%) & Female (\%) & Total \\
$(\mathbf{n}=\mathbf{9 5})$ & $(\mathbf{n = 8 2 )}$ & \\
\hline $0-2$ & 96 & $7(58.33)$ & $5(41.66)$ & $12(57.14)$ \\
$2-4$ & 37 & $3(60)$ & $2(40)$ & $5(23.81)$ \\
$4-6$ & 17 & $1(50)$ & $1(50)$ & $2(9.52)$ \\
$6-8$ & 10 & $1(50)$ & $1(50)$ & $2(9.52)$ \\
$8-10$ & 8 & 0 & 0 & 0 \\
$10-12$ & 9 & 0 & 0 & 0 \\
\hline Total & $\mathbf{1 7 7}$ & $\mathbf{1 2 ( 5 7 . 1 4 )}$ & $\mathbf{9 ( 4 2 . 8 6 )}$ & $\mathbf{2 1 ( \mathbf { 1 1 . 8 6 } )}$ \\
\hline
\end{tabular}

Figures in parentheses indicate percentage

TABLE II DISTRIBUTION OF CRYPTOSPORIDIUM POSITIVE CASES IN RELATION TO SOCIOECONOMIC STATUS* $(\mathrm{n}=177)$

\begin{tabular}{lcc}
\hline Socio-Economic Class & Total Cases & $\begin{array}{c}\text { Cryptosporidium Positive } \\
\text { Cases (\%) }\end{array}$ \\
\hline Class I (> Rs. 10,000) & 13 & $2(15.38)$ \\
Class II (Rs. 5000 - 9999) & 38 & $3(7.89)$ \\
Class III (Rs. 3000 - 4999) & 85 & $8(9.41)$ \\
Class IV (Rs. 1500 - 2999) & 34 & $6(17.65)$ \\
Class V (< Rs. 1500) & 7 & $2(28.57)$ \\
\hline Total & 177 & 21 \\
\hline
\end{tabular}

Figures in parentheses indicate percentage

*Modified Prasad's Classification (Bhaskara Rao, 2002) ${ }^{12}$ 
TABLE III RATE OF INFECTION BY CRYPTOSPORIDIUM IN RELATION TO SOCIODEMOGRAPHIC CHARACTERISTICS

\begin{tabular}{|c|c|c|}
\hline & Characteristics & Total Cases (\%) \\
\hline \multirow[t]{4}{*}{1.} & Diet & \\
\hline & i.Exclusively breastfed & $2 / 39(5.1)$ \\
\hline & ii.Partially breastfed & $9 / 73(12.3)$ \\
\hline & iii.Bottle fed & $10 / 65(15.4)$ \\
\hline \multirow[t]{3}{*}{2.} & Locality & \\
\hline & i.Urban & $10 / 89(11.2)$ \\
\hline & ii.Rural & $11 / 88(12.5)$ \\
\hline \multirow[t]{5}{*}{3.} & Source of Water Supply & \\
\hline & i.Insanitary well & $12 / 28(42.9)$ \\
\hline & ii.Handpump & $3 / 47(6.4)$ \\
\hline & iii.Tap water & $6 / 82(7.3)$ \\
\hline & iv.Boiled/Filtered water & $0 / 20(0)$ \\
\hline \multirow[t]{3}{*}{4.} & Animals at residence & \\
\hline & i.With & $8 / 44(18.2)$ \\
\hline & ii.Without & $13 / 133(9.8)$ \\
\hline \multirow[t]{4}{*}{5.} & Place of defaecation & \\
\hline & i.Field defaecation & $8 / 50(16.0)$ \\
\hline & ii.Insanitary latrines & $7 / 42(16.7)$ \\
\hline & iii.Sanitary latrines & $6 / 85(7.1)$ \\
\hline
\end{tabular}

Figures in parentheses indicate percentage 